\title{
TRAJETÓRIA ASSISTENCIAL NO ÂMBITO DA SAÚdE REPRODUTIVA E SEXUAL - BRASIL, SÉCULO XX
}

Edir Nei Teixeira Mandú ${ }^{1}$

Mandú ENT. Trajetória assistencial no âmbito da saúde reprodutiva e sexual - Brasil, século XX. Rev Latino-am Enfermagem 2002 maio-junho; 10(3):358-71.

Construções tecnoassistenciais em torno dos processos da reprodução e sexualidade, no âmbito do setor de saúde brasileiro, encaminhadas no século passado, são o objeto em discussão. Recupera-se a sua trajetória histórica, com ênfase em três grandes momentos: um primeiro, até os anos 50, quando se assentam as bases de uma responsabilidade pública com a maternidade e difundem-se intervenções médicas moralizantes no campo da sexualidade; um segundo, entre os anos 50 e 70, em que se consolida o cuidado clínico-educativo dirigido ao processo reprodutivo feminino e a complicações do sistema sexual de ambos os sexos; um terceiro, em que se constroem bases políticas mais amplas de atenção à saúde, reprodução e sexualidade.

Descritores: saúde pública, reprodução, sexualidade

\section{THE EVOLUTION OF CARE IN THE AREAS OF REPRODUGTIVE AND SEXUAL HEALTH - BRAZIL, 20 ${ }^{\text {TH }}$ CENTURY}

Technical and practical works on the reproduction and sexuality processes conducted in Brazil, in the last century, are the subject of this article. Therefore, authors review the history and emphasize three moments: the first one, until the 1950's, when the basis of public responsibility is defined specially regarding maternity and medical interventions are carried out in order to moralize the sexuality field; second, between the 1950's and 1970's, when the clinical and educative health care is consolidated and directed to women reproductive process and complications on men and women sexual apparatus; third, when broader political bases are built regarding health care, reproduction and sexuality.

DESCRIPTORS: public health; reproduction; sexuality

\footnotetext{
${ }^{1}$ Professor Adjunto da Faculdade de Enfermagem e Nutrição da UFMT, Doutoranda em Enfermagem pela Escola de Enfermagem de Ribeirão Preto, da Universidade de São Paulo, e-mail: emandu@zaz.com.br
} 
TRAYECTORIA ASISTENCIAL EN EL AMBITO DE LA SALUD REPRODUCTIVA Y SEXUAL - BRASIL, SIGLO XX

Construcciones técnico-asistenciales alrededor de la reproducción y la sexualidad, en el ámbito del sector salud Brasileño en el siglo pasado, son el objeto en discusión. Se recupera la trayectoria histórica con énfasis en tres grandes momentos: un primer momento hasta los años 50, cuando se asientan las bases de una responsabilidad pública con la maternidad y se difunden intervenciones médicas moralizantes en el campo de la sexualidad; el segundo, entre los años 50 y 70, en que se consolida el cuidado clínico-educativo dirigido al proceso reproductivo femenino y a las complicaciones del sistema sexual de ambos sexos; y un tercero, donde se identifican bases más amplias de atención a la salud, reproducción y sexualidad.

DESCRIPTORES: salud pública; reproducción; sexualidad

\section{INTRODUÇÃO}

$\boldsymbol{A}$ trajetória da atenção pública à saúde no âmbito da reprodução e sexualidade, no Brasil do século XX, articulada aos seus específicos determinantes, ainda está por ser reconstituída. A intenção, neste artigo, não é dar conta dessa tarefa, mas aproximar-se desse percurso, reunindo informações dispersas em estudos que exploram ângulos diversos da prática em saúde e daquela específica atenção no país, destacando proposições políticas, modelos organizacionais e incorporações tecnológicas.

No século XX, ocorreram expressivas mudanças na interpretação e efetivação de direitos em saúde, nos padrões de saúdedoença, nos conhecimentos médicos, nos modelos e práticas assistenciais. Surgiram novas construções técnico-científicas, serviços, medidas e ações públicas e privadas em saúde, intermediados por lutas sociais em prol de condições mais dignas de vida e políticas públicas favoráveis. Nesse século as sociedades ousaram pensar a saúde com uma intencionalidade prática ${ }^{(1)}$.

Com essas mudanças demarca-se o que se convencionou denominar sistema médico, que contempla significativas inclusões tecnológicas no cuidado à vida humana relativas a instrumentos e meios diagnósticos, controle e tratamento da saúde, processos normativos, relacionais, saberes e sistemas organizacionais de cuidados, através de práticas denominadas comumente de saúde pública e assistência médica ${ }^{(2,3-4)}$. Nesse movimento, desenha-se um campo de atuação político-social voltado à atenção a necessidades nas esferas da reprodução e sexualidade. No cuidado a essas dimensões da vida humana, são construídas tecnologias diversas, em dados modelos organizacionais, a partir de necessidades e possibilidades identificadas e valorizadas no interior de processos sociais e políticos em curso no país.

Essas construções, em linhas gerais, circunscrevem-se: à construção social do papel materno no cuidado da saúde dos filhos; à conformação de certos padrões de comportamento sexual; ao controle quantitativo da procriação; ao cuidado médico com a gravidez, parto, puerpério e funcionalidade do sistema reprodutivo/sexual; à ampliação de direitos nessas esferas. Essas formulações 
apresentam-se de modo peculiar, em momentos distintos da prática em saúde, e podem ser classificadas em, pelo menos, três grandes fases: a da maternidade e sexualidade como constituintes do projeto higienista/ eugenista, do final do século XIX a meados do século $X X$; a da reprodução como constituinte do projeto médico, do final da fase anterior à década de 70; a da saúde, sexualidade e reprodução, como constituintes dos direitos sociais, abrangendo, particularmente, as décadas de 80 e 90.

\section{O PROJETO HIGIENISTA/EUGENISTA NO BRASIL: A SEXUALIDADE E A MATERNIDADE SOB CONTROLE}

No final do século XIX, a ciência e a técnica em saúde são pouco desenvolvidas no Brasil. As instituições governamentais de saúde restringem-se praticamente a órgãos de fiscalização e regulamentação das condições sanitárias do meio $^{(3)}$. A população recorre diretamente a médicos, cirurgiões, barbeiros, curandeiros, parteiras e curiosas, sendo os pobres assistidos por iniciativas filantrópicas ${ }^{(2)}$.

A assistência ao parto e o tratamento de infecções do aparelho genital (problemas venéreos) são realizados no espaço dos domicílios. Os governos quase não participam desses e de outros cuidados. Os conhecimentos técnico-científicos em saúde, reprodução e sexualidade são bastante restritos $^{(3-5)}$.

Predominam as atividades fundiárias e as relações escravocratas, sob o domínio colonial português, e, nesse contexto, a participação estatal em saúde é praticamente inexistente, resumida apenas a algumas medidas de caráter mais geral e/ou de auxílio financeiro à filantropia.

A prática médica preocupa-se com o combate da desordem social, considerada causa dos problemas de saúde existentes. Em suas bases, encontra-se um projeto higienista, articulado à ordem e à moral. A família constituise o grande alvo das suas medidas, voltadas à construção de comportamentos interpretados como favoráveis ao controle da mortalidade (sobretudo infantil) e estímulo à natalidade, postulando-se a restrição do exercício da sexualidade, sobretudo das mulheres, às relações conjugais e à procriação*(6).

É no início do século XX, no contexto de reorganização produtiva, política e geográfica do Brasil republicano, que se localizam iniciativas mais amplas do poder público no âmbito da saúde, acompanhadas da criação/ adoção de tecnologias como campanhas educativas, policiamento sanitário, saneamento de portos e cidades, imunização de massa e isolamento de doentes ${ }^{(3)}$.

Nesse momento, várias unidades burocráticas de saúde pública são criadas, com responsabilidade consultiva, normativa e executiva, generalizando-se normas e medidas legais em torno daquelas práticas. $\mathrm{O}$ modelo tecnológico organizado viabiliza-se através de institutos de pesquisa, laboratórios e algumas poucas unidades de assistência. Em seu interior, são produzidos novos conhecimentos

\footnotetext{
* O discurso higienista, no Brasil, articula saúde-doença à ordem-desordem social. Dirigido à reprodução e sexualidade, evidencia as responsabilidades da mulher no cuidado da saúde infantil, na prevenção de agravos à saúde da família, estimulando a natalidade e a restrição do sexo à procriação ${ }^{(6)}$
} 
científicos em torno da etiologia, meios diagnósticos e medidas de prevenção das enfermidades coletivas contagiosas, com base, sobretudo, na bacteriologia, imunologia e engenharia sanitária $^{(7)}$. A saúde e a doença são encaradas como processos coletivos, decorrentes da agressão do meio social/natural sobre o corpo biológico. O modelo construído e as tecnologias aplicadas voltam-se à descoberta dos agentes contaminantes, ao seu isolamento, à destruição dos vetores e ao aumento da resistência dos indivíduos às doenças $^{(4)}$.

A atenção pública à reprodução, nesse contexto, é restrita, caracterizando-se basicamente pelo padrão de interferência familiar dos anos anteriores. Frente à sexualidade, as ações governamentais circunscrevem-se ao controle médico dos problemas venéreos. No início do século XX, a sífilis apresenta-se como um dos grandes problemas urbanos, enfrentado através de medidas de alerta, de educação moral e de controle sanitário. Em hospitais, várias áreas são construídas para o seu tratamento, aplicamse medidas educativas à população, práticas de inspeção são dirigidas a amas-de-leite e militares e institui-se a obrigatoriedade do exame pré-nupcial ${ }^{(8)}$.

Planos e ações governamentais mais abrangentes, nas esferas em questão, são encaminhados somente a partir dos anos $20 /$ 30 , quando a saúde pública compromete-se com novos processos sociais e passa a desenvolver ações específicas dirigidas à infância, maternidade e profilaxia em geral.

Nesses anos, grupos sociais diversos colocam em cheque o regime político liberalrepublicano e canalizam, para o Estado, pressões por melhores condições de vida e de atenção à saúde. O combate governamental da pobreza e doença apresenta-se como uma condição fundamental à estabilização política e organização de um novo mercado de trabalho, favorável ao desenvolvimento inicial da industrialização nacional.

Desse modo, ao lado da preocupação com as questões do meio, novos padrões de higiene são traçados e implementados através de práticas educativas sistemáticas. Desafios como a desqualificação física para o trabalho e problemas de saúde infantil suscita medidas preventivas e corretivas articuladas em torno da chamada educação sanitária ${ }^{(3)}$.

Nos anos 20, desenvolve-se a base inicial da atenção médico-previdenciária no Brasil, dirigida a trabalhadores inseridos no mercado urbano de setores de ponta, nos espaços geográficos que primeiro se industrializam ${ }^{(9)}$. Essa nova organização preocupa-se com processos de cura, mediante serviços específicos, distinguindo-se dos voltados ao controle das doenças, via medidas de higiene, educação sanitária e organização administrativa dos serviços ${ }^{(4)}$.

Nos anos 30, estrutura-se uma explicação médico-sanitária, construída com a participação de sanitaristas dos grandes centros brasileiros, influenciados por experiências americanas, manifestando-se uma nova compreensão da saúde-doença, que passa a ser predominantemente interpretada como fenômeno individual/coletivo determinado pelos próprios indivíduos ${ }^{(4)}$. A saúde pública passa a ocupar-se sobretudo da educação dos indivíduos, visando ao controle das doenças através de ações pedagógicas junto à família.

Sob orientação do modelo médicosanitário, a nova organização da assistência toma como eixo os postos e centros de saúde, 
organizados em uma estrutura regionalizada, comandada pelo setor público, com a participação específica de sanitaristas. As atividades desenvolvidas associam às ações educativas o controle das doenças, através do diagnóstico e tratamento precoces ${ }^{(4)}$. No interior desses serviços alarga-se a atenção governamental à reprodução, maternidade e a aspectos da sexualidade, orientada por uma visão que valoriza a educação como via essencial à saúde. Como parte dos cuidados, são eleitas medidas educativas de estímulo e controle da amamentação, de cuidado materno com a vida infantil e de desenvolvimento de comportamentos para a prevenção dos problemas venéreos.

Os anos 20 são considerados centrais no combate das doenças venéreas, incluindo a participação do governo federal e a de um grupo de médicos e cientistas da Sociedade Brasileira de Dermatologia e Sifilografia. A preocupação com a formação de trabalhadores hígidos, especialmente com a diminuição do fluxo imigratório no Brasil, torna explícitas questões como o problema da sífilis e o sentido moral que a acompanha. Ajuíza-se que a mistura de raças no Brasil é o resultado de uma promiscuidade que, por meio de estratégias eugênicas*, poderia ser superada. A hereditariedade é controlada via medidas normalizadoras da sexualidade. Apregoam-se os exames pré-nupciais, regras são estabelecidas a respeito do casamento e, através de ações educativas de caráter científico e moralizador, os comportamentos sexuais são disciplinados ${ }^{(10)}$.

Formula-se uma política nacional de combate às doenças venéreas (e lepra), criando-se, em 1920, a primeira legislação brasileira nesse terreno. Institui-se uma inspetoria com a função de fiscalizar os serviços, formular normas técnicas, organizar nacionalmente a profilaxia e intervir medicamente em pessoas recolhidas em asilos e prisões. Em 1921, estrutura-se um grande laboratório para diagnóstico da sífilis e fabricação de medicamentos específicos e preservativos. Alastram-se, pelo país, dispensários antivenéreos, alguns localizados nos principais portos brasileiros ${ }^{(8)}$.

$\mathrm{Na}$ proteção médico-sanitária da gravidez e vida infantil, utilizam-se tecnologias como estímulo à amamentação natural, o recurso das amas-de-leite (práticas presentes anteriormente), educação materna para o cuidado de bebês, programas de higiene da gravidez (autocuidado com a gravidez e a alimentação apropriada), distribuição de leite a gestantes e nutrizes pobres, além de práticas de visitação domiciliar ${ }^{(3,6,8,10-11)}$. Às práticas educativas juntam-se alguns cuidados médicos individualizados, de diagnóstico e tratamento precoces dos problemas, que passam a ganhar cada vez mais espaço com o avanço da assistência médica ${ }^{(11)}$. Emprega-se um discurso de higiene infantil dependente dos padrões de moralidade da família e cuidado materno, que propõe regras e mudanças de comportamentos a seus membros ${ }^{(6)}$.

Entre 1930 e 1945, novas estruturas burocrático-assistenciais são criadas no campo da saúde pública ${ }^{(3)}$. Ao mesmo tempo, aprofunda-se a organização da atenção médica, voltada para trabalhadores inseridos

\footnotetext{
* O discurso eugenista ocupa-se do aprimoramento da raça, estimulando sua depuração mediante a aplicação de medidas educativas moralizantes e de controle da hereditariedade ${ }^{(10)}$
} 
no mercado de trabalho em desenvolvimento. À medida que a saúde pública sedimenta sua atuação, a atenção previdenciária projeta-se favorecida pelo financiamento do Estado, inicialmente mediante auxílios e subvenções e, mais tarde, também através da compra de serviços $^{(9)}$.

Aumenta o número de unidades de saúde pública, sob encargo estadual, especialmente de centros e postos de saúde e postos especiais, responsáveis, entre outros processos, pelo controle de doenças transmissíveis (incluindo as venéreas) e pela proteção médica de gestantes e crianças. Concomitantemente, expandem-se significativamente serviços hospitalares públicos e privados ${ }^{(3)}$. Em 1937, é criada a Diretoria de Proteção à Maternidade e Infância, entre outras razões, para apoio técnico e financeiro às instituições públicas e privadas de assistência materno-infantil ${ }^{(11)}$.

A partir dos anos 40, a assistência médica passa a integrar mais efetivamente os serviços de saúde pública, nas áreas estabelecidas de controle das doenças transmissíveis e também na atenção à maternidade e infância. Depois de meados da década de 40, a assistência materno-infantil firma-se, apoiada no Departamento Nacional da Criança. Normas, planos e programas integrados de proteção pública e privada à maternidade, infância e adolescência, incluindo auxílio financeiro e programas especiais, como alimentares e educativos, passam a ser articulados por essa estrutura ${ }^{(11)}$.

Com o término da II Guerra Mundial, mudanças econômicas e políticas marcam o cenário mundial. No Brasil, luta-se por democratização em meio a substantivas alterações no desenvolvimento das forças produtivas. Aceleram-se a industrialização e o processo de urbanização, e inúmeras tensões e pressões marcam as relações do Estado com a sociedade civil, face ao acesso diferenciado a condições de vida e saúde. Assim, como parte de um processo em que se garantem as bases sociais e políticas para o crescimento econômico nacional são contempladas, no setor saúde, propostas mais abrangentes de atenção ao grupo materno-infantil ${ }^{(3)}$. Solidificam-se ações públicas voltadas à maternidade e infância, num cenário em que se aprofunda a preocupação com a formação de quadros humanos para o crescente trabalho industrial, luta-se por melhoria do acesso a serviços e produzem-se novos modos de atuar no campo.

Na saúde pública, essa assistência orienta-se pela puericultura, que, em seu desenvolvimento, mantém/introduz tecnologias de controle da gestação, cuidado materno à criança, controle pré-nupcial da saúde, dentre outras, desenvolvidas como parte prática da rede de postos e centros de saúde e dos denominados clubes de mães. No reequipamento de instituições materno-infantis, na expansão de postos de puericultura, de postos e centros de saúde pública, de maternidades e serviços de pediatria públicos e privados, somam-se investimentos estatais nacionais e recursos internacionais ${ }^{(11)}$.

Em síntese, pode-se dizer que, na primeira metade do século XX (dos anos 20 aos 50), assentam-se as bases de uma responsabilidade governamental com a maternidade, em consonância com a importância dada ao seu controle para o desenvolvimento econômico-social do Brasil. No âmbito da saúde pública, a atenção à maternidade organiza-se ligada à preocupação 
com a saúde infantil, apoiada eminentemente em tecnologias educativas, dirigidas a mulheres, inicialmente com vistas ao cuidado apropriado das crianças e família e, mais tarde, também em função da necessidade identificada de proteção mais ampla daquele processo. Os cuidados desenvolvidos em torno da sexualidade restringem-se à conformação de um determinado padrão de moralidade interpretado, hegemonicamente, como apropriado à época e ao controle das doenças de transmissão sexual, mediante a aplicação de tecnologias educativas que disciplinam o exercício conjugal e sexual, sobretudo da vida feminina.

\section{O AVANÇO DA ASSISTÊNCIA MÉDICA: A REPRODUÇÃO EM FOCO}

A reprodução e a sexualidade são incorporadas como objetos de políticas específicas e prioritárias, sobretudo a primeira, somente na segunda metade do século $X X$, no processo de avanço da industrialização nacional e fortalecimento dos movimentos e forças sociais, no tempo em que se alarga a interferência médica pública e privada em saúde.

Nos anos 60, manifestam-se problemas de saúde cada vez mais complexos no Brasil, relacionados à aceleração da industrialização, urbanização e deterioração das condições de vida, num momento de reordenação econômica, chamado de "milagre brasileiro", comandado pelo regime político autoritário (efetivamente instalado em 1964).

Desenvolve-se, no setor saúde, um discurso e prática preventivistas, baseados no paradigma da história natural das doenças (elaborado nos anos 40), que aponta o social como um de seus fatores causais, relacionado ao hospedeiro e ambiente ${ }^{(12)}$. Articulada por sanitaristas, essa nova proposta enfatiza a integralidade do doente e a aplicação de medidas preventivas de saúde familiar, visando à superação da dicotomia cunhada entre a saúde pública e a atenção médica ${ }^{(4)}$.

Ao contrário, a retração da saúde pública e o seu distanciamento da assistência médica aprofundam-se ainda mais, nos anos seguintes. As práticas individualizadas e o uso de tecnologias curativas solidificam-se no processo de crescimento dessa última, com a privatização do setor e com o crescimento do complexo médico-industrial, ambos incrementados por incentivos fiscais, compra de serviços pelo Estado ${ }^{(9)}$ e produção contínua de novos conhecimentos técnico-científicos.

A partir de meados de 70, no quadro de crise econômica e social que acompanha o esgotamento do modelo desenvolvimentista dos anos anteriores, confronta-se a permanência do acesso diferenciado ao consumo de bens e serviços sociais em geral e no campo da saúde. Nesse contexto, novas medidas governamentais são delineadas, como a extensão da assistência à saúde a alguns setores assalariados, limitadas pela contraditória manutenção das bases salariais do financiamento em saúde ${ }^{(9)}$. A política de saúde assume, além da extensão da assistência médica à parcela de mulheres pobres não inseridas no mercado de trabalho, a oferta de benefícios como o salário maternidade ${ }^{(11)}$.

Demandas crescentes por atenção médica e a crise financeira da Previdência Social, em fins de 1970, geram a eleição de medidas governamentais restritivas dos gastos, 
valorizando-se investimentos na assistência básica à saúde e a utilização, nesta, de tecnologias simplificadas ${ }^{(4)}$. Mundialmente, o ideário da Atenção Primária à Saúde, sob o marco da medicina comunitária, propunha medidas voltadas à reorganização dos serviços, para assistência precoce e contínua de cunho preventivo e curativo, destacando a expansão e melhoria do primeiro nível tecnológico do setor. Assim, sob a influência desses dois processos, o Ministério da Saúde reformula as diretrizes gerais da assistência à saúde e, em 1974/1975, também a política nacional de saúde ao grupo materno-infantil, oficializandoa através do Programa Materno-Infantil (PMI).

Por meio desse programa são formalizadas ações de assistência à gravidez, parto e puerpério, de estímulo à amamentação e medidas para espaçamento entre as gestações, dirigidas a mulheres entre 15 e 49 anos, consideradas partes dos grupos mais vulneráveis, delimitados por meio de critérios pautados no conceito de risco ${ }^{(13)}$. Os homens ficam de fora dessas proposições, negandose, no plano da política proposta, a participação, responsabilidade e os riscos reprodutivos a que estes também estão sujeitos.

As novas tecnologias orientam-se para a assistência ao ciclo grávido-puerperal, a problemas ginecológicos (câncer e doenças venéreas femininas) e ao controle da fertilidade feminina. Ações educativas, realizadas nos serviços e nos domicílios, somam-se ao incremento da terapêutica medicamentosa e à prevenção e tratamento de agravos controláveis através de tecnologias como imunização, suplementação alimentar e controle de problemas menos complexos, do ponto de vista médico, como parasitoses, anemias, infecções urinárias, hipertensão, entre outros.
Prevêm-se, inicialmente, orientação e distribuição de meios contraceptivos nos serviços de prevenção da gestação de risco e, mais tarde, a sua expansão para os demais espaços de execução do programa ${ }^{(11)}$. Com o estímulo ao espaçamento entre as gestações em situações consideradas de risco, justificado na necessidade de prevenção da mortalidade infantil e materna, revela-se a tônica da interferência governamental proposta na questão do controle/planejamento da reprodução. Apesar das divergências em torno da questão, a necessidade de controle do crescimento populacional nos países pobres encontrava-se presente no cenário mundial, desde os anos 50, e, na América Latina e Brasil, desde os anos $60^{(14)}$. Aqui, medidas de controle do processo reprodutivo já vinham sendo desenvolvidas, direcionadas a mulheres, independentemente das posições oficiais do governo brasileiro. Não existiam no Brasil, até - final da década de 70, propostas governamentais específicas referentes ao planejamento/controle da prole, mas grupos e instituições filantrópicas e privadas, apoiados por instituições internacionais e pelo próprio governo, disseminavam, entre as populações mais pobres, tecnologias contraceptivas, como o DIU, os hormonais e a esterilização ${ }^{(11)}$.

Nos anos 70 , inúmeras clínicas e maternidades são construídas no Brasil, crescendo o número de leitos públicos e privados para o cuidado aos problemas relacionados ao ciclo grávido-puerperal ${ }^{(11)}$. 0 trabalho das parteiras/obstetrizes, até então valorizado, é praticamente substituído pelo trabalho de profissionais especializados (sobretudo médicos obstetras).

Nesse momento, a interferência na esfera da sexualidade continua a se restringir 
a problemas orgânicos decorrentes da atividade sexual e do próprio processo da reprodução, abarcando, especialmente, o controle de problemas relativos ao aparelho sexual feminino e masculino, através das especialidades de ginecologia e urologia. Os problemas venéreos, que, por muito tempo, foram objeto específico de atenção, com o avanço da terapêutica medicamentosa (como os antibióticos), passam a ser controlados via práticas clínico-educativas sedimentadas nas unidades ambulatoriais.

Essas novas construções políticas e práticas em relação à reprodução e sexualidade firmam um campo específico de assistência, dirigida à gestação, parto e puerpério e a complicações do sistema reprodutor/sexual (controle de infecções e anomalias genitais masculinas e ginecopatias e infecções femininas). Amplia-se a assistência médica especializada, por meio da atenção ambulatorial e hospitalar, através de serviços públicos, do complexo previdenciário e da rede privada.

A assistência médica à saúde desenvolvida orienta-se por uma visão clínica e curativa das doenças, ao mesmo tempo em que Ihe dá consistência. Mesmo no campo da saúde pública, a explicação (via epidemiologia clássica) e atuação em problemas coletivos submetem-se à lógica dessa visão(15). As intervenções dirigem-se predominantemente à correção dos problemas físicos, negando-se, no plano assistencial, os processos socioculturais que se encontram na base dos processos vitais, como a reprodução e sexualidade. Incorpora-se o uso crescente de tecnologias medicamentosas, práticas cirúrgicas $^{(12)}$, instrumentos e recursos diagnósticos (como os de radioimagem) produzidos e atualizados continuamente via mercado.

Nesse contexto, como parte da histórica correlação entre produção - reprodução mulheres, aprofunda-se a perspectiva que explica a reprodução como fenômeno afeito sobretudo à dinâmica orgânica feminina, numa clara restrição e homogeneização das problemáticas socioculturais vivenciadas pelo grupo $^{(16-17)}$, acompanhada da negação do seu caráter relacional. Os conhecimentos e práticas produzidos no âmbito da sexualidade também se centralizam em processos fisiopatológicos, firmando-a como um processo eminentemente biológico, limitado na relação sexo - reprodução.

Com os anos 70, distingue-se o cuidado público dirigido à esfera reprodutiva feminina, como atenção à saúde materna. Ao mesmo tempo, torna-se cada vez mais explícita a necessidade de o Estado comprometer-se com medidas mais abrangentes de atenção à saúde, reprodução e sexualidade. Estas passam a ser demandadas nos anos seguintes, de modo particular pelas e para as mulheres, junto à afirmação de seus direitos e crítica à visão naturalizada adotada em torno dos seus processos de vida e saúde, estendendo-se também a outros grupos como o de adolescentes.

\section{SAÚDE, REPRODUÇÃO E SEXUA- LIDADE COMO DIREITOS}

Na segunda metade dos anos 70 e início dos anos 80, a interpretação médica vigente, centrada em questões de ordem física, tornase amplamente questionada e mobilizada por outras abordagens que dão vitalidade às relações entre saúde e condições socioculturais 
vividas pelos vários grupos e, especificamente, por mulheres.

Propaga-se uma abordagem social da saúde-doença e cura(15) e, através de perspectivas feministas/de gênero, desnaturalizam-se os papéis e as relações entre homens e mulheres, desencobrindo os seus significados para a saúde feminina(17). Contrapondo-se à visão prevalecente, ganha corpo uma leitura articulada dos processos biológicos, psicoemocionais e socioculturais da vida humana, fornecendo-se novas bases para uma compreensão mais global da saúde, da reprodução e sexualidade. Os anos 80 são marcantes nessa revisão, através de vários processos sociais, em que se destacam os movimentos pela reforma sanitária e os com participação de mulheres e feministas ${ }^{(18)}$.

Esses anos são definitivamente marcados por reformas nas políticas sociais. A crise econômica, que se manifesta após o "milagre econômico" dos anos anteriores, alcança seu auge nos anos 80 , acompanhada de uma abertura democrática gradual. Oficializa-se, na Constituição Federal de 1988 e em outras legislações secundárias, a proposta de criação do Sistema Único de Saúde, pautada nos princípios da universalidade, eqüidade e integralidade da atenção e na afirmação da saúde como direito de todos e dever do Estado. Críticas contundentes são dirigidas ao duplo modelo, à perspectiva racionalizadora adotada e à centralização da atenção em processos de cura. Movimentos e iniciativas voltados à remodelação da assistência enfatizam a necessidade de construção de modelos tecnológicos mais abrangentes, inspirados no resgate local da relação saúde - qualidade de vida.

Diferentes posições difundem-se no cenário nacional, confrontando-se defensores da especialização e alta absorção de insumos e equipamentos na atenção à saúde via mercado, articuladores de um modelo centrado na atenção básica, alternativo à redução de gastos públicos em saúde, e atores favoráveis a mudanças radicais para a democratização, universalização e integração do setor ${ }^{(4)}$.

Defesas em prol da extensão de direitos femininos em saúde dão um novo tom, através da defesa de propostas e experiências de reconstrução da atenção, fundada na consideração às especificidades das condições de vida das mulheres, num claro confronto aos limites das respostas públicas/governamentais elaboradas nos anos anteriores. Não só se debatem em todo o território questões de saúde da mulher, como se elege um outro olhar sobre o feminino, as diferenças, criticando-se qualquer forma de subordinação social ${ }^{(18-19)}$. Necessidades afeitas à reprodução e sexualidade passam a ser vistas no contexto da atenção integral à saúde e explicadas com base nas relações sociais de classe, raça/etnia, gênero, geração, em que se resgata a relação entre o cotidiano e o contexto global.

Essas específicas manifestações e reconstruções articuladas em torno de demandas pela ampliação de direitos sociais femininos evidenciam-se, como em todo o mundo, como um tema diretamente vinculado à vida desse segmento, ficando novamente $\mathrm{o}$ homem, enquanto sujeito com direitos específicos, marginalizado nesse processo.

Mundialmente, contribuições de grupos feministas, de mulheres, de acadêmicas/ cientistas e de organismos governamentais/não governamentais, estimulavam e incrementavam o processo nacional. Em 1975, na I Conferência Internacional da Mulher, 
realizada na cidade do México, a ONU recomenda aos países membros medidas para a eliminação das desigualdades entre homens e mulheres e conquista da paz mundial ${ }^{(18)}$. Em 1984, em Amsterdã, no Tribunal Internacional do Encontro sobre Direitos Reprodutivos, definem-se estratégias políticas de internacionalização da luta por sua ampliação, criticando-se posturas restritas a perspectivas controlistas em torno da concepção ${ }^{(19)}$. Em 1985, na II Conferência Internacional da Mulher, realizada em Copenhague, acrescentam-se, às recomendações da primeira, linhas de atuação especificamente voltadas à saúde, educação e trabalho feminino ${ }^{(18)}$.

No Brasil, o debate e posições acerca dos direitos das mulheres incorporam questões como a superação da violência presente nas relações e práticas em saúde feminina e valorização das suas experiências corporais, resgatando-se o sentido mais amplo da sexualidade no interior dos serviços. Além disso, reforça-se a necessidade de ampliação do acesso, de melhoria da qualidade das ações/ serviços de saúde, levando-se em consideração as implicações médicas e éticas das novas tecnologias introduzidas na assistência $^{(19)}$. Políticas de saúde, mudanças na legislação e o papel do Estado são tratados como pontos essenciais à implementação das mudanças pretendidas.

As lutas sociais encaminhadas no Brasil resultam em negociações com órgãos governamentais, antes e por ocasião da Primeira Conferência Nacional de Direitos da Mulher, realizada em Brasília, em 1986, quando se sintetizam interpretações/proposições em saúde feminina. No início dos anos 80 , o governo, em articulação com representantes de grupos feministas, projeta políticas e propostas assistenciais mais amplas, dirigidas à saúde feminina. Como um dos frutos desse processo, em 1983/1984, o Ministério da Saúde lança o Programa de Atenção Integral à Saúde da Mulher (PAISM).

Esse Programa é apresentado no contexto da política de expansão e consolidação da rede de serviços básicos de saúde, sendo preconizado como parte da política das Ações Integradas de Saúde (AIS), num cenário de contraposições e lutas por reformas mais amplas no sistema de saúde. Um de seus méritos foi o de oficializar o conceito de integralidade como princípio fundamental de organização da atenção à mulher, traduzido como atenção a "todas as necessidades de saúde" da adolescência à terceira idade feminina. Em suas proposições, o novo Programa prevê a implementação nacional de medidas clínicas e educativas, a partir de critérios epidemiológicos, para acompanhamento da gestação, parto, puerpério, controle das doenças sexualmente transmissíveis, câncer ginecológico, além de medidas de anticoncepção e tratamento da infertilidade ${ }^{(20)}$. Para essas últimas, são projetadas ações de orientação, acompanhamento da saúde e a oferta de meios apropriados, sem qualquer tipo de coerção.

Ainda nos anos 80 , com o crescimento das DSTs e com o avanço da AIDS, iniciativas governamentais resgatam e ampliam medidas adotadas de prevenção, diagnóstico e controle desses problemas. Através da Coordenação Nacional de Doenças Sexualmente Transmissíveis/Aids, estimula-se a implantação municipal de ações educativas preventivas e medidas de diagnóstico e tratamento desses problemas.

Em 1989, o Ministério da Saúde divulga 
as bases nacionais da atenção ao adolescente, através do Programa de Saúde do Adolescente (PROSAD), em decorrência das pressões advindas de organismos internacionais (OMS/ FNUAP/UNICEF) e de grupos nacionais, face à necessidade de melhoria das condições de vida e saúde do grupo. A preocupação com o controle da fecundidade, exposição às DSTs/ AIDS, violência e maus tratos ao grupo dão a tônica das medidas propostas. As tecnologias desenhadas circunscrevem-se a medidas de aconselhamento sexual, incluindo informações e oferta de meios de controle da contracepção e prevenção das DSTs/AIDS, ações de detecção e tratamento de infecções genitais e controle de agravos no ciclo grávidopuerperal $^{(21)}$. Com base no princípio da integralidade das ações de saúde, formalmente, são priorizadas ações básicas dirigidas aos adolescentes de ambos os sexos, indicandose a sua vinculação às ações direcionadas à saúde feminina e saúde familiar.

A partir de 1992, crianças, adolescentes e adultos jovens passam a ser prioridades no projeto nacional de prevenção e controle desses agravos, incrementando-se, através de convênios específicos, a implementação de ações locais de caráter educativo para práticas sexuais seguras, além da adoção de tecnologias para seu diagnóstico precoce e tratamento $^{(22)}$.

Na última década do século $X X$, como alternativa à remodelação da assistência básica e, em tese, da atenção nos demais níveis do sistema, inicia-se um processo de implantação, em vários municípios brasileiros, do Programa de Agentes Comunitários em Saúde (1991) e Programa Saúde da Família (1994). Sob o argumento de que a qualidade de vida das pessoas e do seu ambiente deve ser o centro da atenção à saúde, propõe-se como estratégia uma relação direta das equipes de saúde com os núcleos familiares das comunidades sob sua responsabilidade ${ }^{(23)}$. Essa orientação intenciona articular as várias ações assistenciais aos grupos e suas diferentes necessidades, incluindo o cuidado à reprodução e sexualidade nas diferentes fases etárias, visando à universalização do acesso e à garantia da integralidade assistencial.

Essas experiências, em encaminhamento, demandam avaliações sobre seus reais contornos e seus significados para a melhoria da saúde dos diferentes grupos, incluindo a saúde reprodutiva e sexual. $\mathrm{O}$ cenário atual caracteriza-se por um conjunto de limites em que se destaca o de investimentos financeiros público-governamentais nas áreas sociais, e em muitos locais aquelas práticas mantêm um perfil centrado no desenvolvimento de ações clínico - educativas restritas, a par de intervenções em processos socioculturais concretos que tornam as pessoas mais ou menos vulneráveis aos diferentes agravos.

\section{CONSIDERAÇÕES FINAIS}

Para as mudanças tecnológicas projetadas nos anos $80 / 90$, tem sido relevante o debate sobre a saúde reprodutiva e sexual feminina e os direitos pertinentes travado mundialmente, em particular com a Conferência Internacional sobre População e Desenvolvimento, de 1994, e IV Conferência Internacional sobre a Mulher, de 1995. Esses processos abrem espaço à compreensão da reprodução e sexualidade como esferas de direitos singulares e à afirmação da cidadania e autodeterminação, dos diferentes sujeitos.

No Brasil, na atualidade, construções 
acadêmicas vêm tentando dar visibilidade e ampliar tais entendimentos, sob o marco da integralidade da vida e saúde, apoiadas no debate da eqüidade de gênero e no entendimento da reprodução e sexualidade como processos relacionais, vividos de modo peculiar por mulheres e homens, revelando um campo singular de necessidades e direitos relativos a esse último segmento.

No início deste novo século, a efetivação dos direitos reivindicados, considerada a sua concreticidade, mantém-se como um dos grandes desafios a serem enfrentados no setor e fora dele, considerado o caráter restritivo das políticas econômico-sociais, no contexto de inserção nacional nas relações globalizadas.

Para além do significativo papel que vem sendo exercido por comunidades acadêmicas, apresenta-se como necessária a retomada de uma política de movimento - de denúncia, de enunciação de necessidades, de construção de novas alternativas e estratégias para a obtenção da saúde - em articulação com as lutas gerais da sociedade. A participação da

\section{REFERÊNCIAS BIBLIOGRÁFICAS}

1. Berlinguer G. Salud y ciudadania en dos finales de siglo. Rev Saúde em Debate 1996 setembro; 52:104-5.

2. Singer $P$, Campos $O$, Oliveira EM. Prevenir e curar: 0 controle social através dos serviços de saúde. Rio de Janeiro (RJ): Forense-Universitária; 1988.

3. Iyda M. Cem anos de saúde pública: a cidadania negada. São Paulo (SP): Unesp; 1994.

4. Merhy EE. A rede básica como construção da saúde pública e seus dilemas. In: Merhy EE, Onocko R, organizadores. Agir em saúde: um desafio para o público. São Paulo (SP): Hucitec; 1997. p.71-112.

5. Rezende J. Conceito, propósitos, súmula histórica. In: Rezende J. Obstetrícia. $5^{a}$ ed. Rio de Janeiro (RJ): Guanabara Koogan; 1988. p.1-22.

6. Nunes SA. A medicina social e a questão feminina. Physis: Rev de Saúde Coletiva 1991; 1(1):48-76.

7. Costa NRC. Lutas urbanas e controle sanitário: origens das políticas de saúde no Brasil. Petrópolis (RJ): Vozes; 1985. sociedade em práticas de controle social é fundamental, em intervenções políticas em prol de mudanças substanciais nas relações entre governos e sociedade, viabilizando tanto $o$ controle como a participação criativa e comprometida da sociedade nas várias formas de gestão/efetivação das políticas sociais/de saúde.

Localiza-se a necessidade de fortalecimento e construção de práticas de controle e participação como instrumentos democráticos, na geração de políticas públicas favoráveis à superação das desigualdades, discriminações e preconceitos, que afetam negativamente a vida, a saúde, a reprodução e sexualidade. Nesse movimento, a construção de modelos assistenciais e incorporação de tecnologias não pode perder de vista, política, ética e tecnicamente, a totalidade humana, o direito à vida com qualidade e a reafirmação dos princípios do Sistema Único de Saúde, sem o que não se poderá galgar uma melhor saúde, para todos, no campo da reprodução e sexualidade.

8. Carrara S. A Aids e a história das doenças venéreas no Brasil: do final do século XIX até os anos XX. In: Loyola $A$, organizadora. AIDS e sexualidade: o ponto de vista das ciências humanas. Rio de Janeiro (RJ): RelumeDumará; 1995. p.73-108.

9. Cohn A. Mudanças econômicas e políticas de saúde no Brasil. In: Laurell AC, organizadora. Estado e políticas sociais no neoliberalismo. São Paulo (SP): Cortez; 1995. p.225-44.

10. Marques VRB. Doenças sexualmente transmissíveis: a intervenção sobre a sexualidade. Rev Saúde em Debate 1992 julho; 32:78-83.

11. Canesqui AM. Assistência médica e a saúde e reprodução humana. Campinas: Núcleo de Estudos de População - NEPO/UNICAMP; 1987.

12. Nunes ED. Saúde coletiva: história de uma idéia e de um conceito. Rev Saúde e Sociedade 1994; 3(2):5-21.

13. Ministério da Saúde (BR). Coordenação de Proteção Materno-Infantil. Programa de Saúde Materno-Infantil. Brasília (DF): Ministério da Saúde; 1975.

14. Barroso C. As mulheres e as Nações Unidas: as linhagens do plano mundial de população. Tempo Social: Rev. de Sociologia da USP 1989; 1(1):183-97. 
15. Gonçalves RBM. Tecnologia e organização social das práticas de saúde: características tecnológicas do processo de trabalho na rede estadual de Centros de Saúde de São Paulo. São Paulo (SP): Hucitec; 1994.

16. Loyola MA. Sexualidade e reprodução. Physis: Rev de Saúde Coletiva 1992; 2(1):93-105.

17. Fonseca RMGS. A construção do saber instrumental na saúde da mulher. In: Scavone L, organizadora. Tecnologias reprodutivas: gênero e ciência. São Paulo (SP): Editora da Universidade Estadual Paulista; 1996. p.61-9.

18. Valéry FD. Ã la croisée des chemins: mulher e cidadania na nova ordem social In: Fonseca RMGS, organizadora. Mulher e cidadania na nova ordem social. São Paulo (SP): Núcleo de Estudos da Mulher e Relações Sociais de Gênero/USP; 1996. p. 27-42.

19. Ávila MB. Modernidade e cidadania reprodutiva. Rev Estudos Feministas 1993; 2:382-93.

20. Ministério da Saúde (BR). Centro de Documentação do Ministério da Saúde. Assistência Integral à Saúde da Mulher: bases de ação programática. Brasília (DF): Ministério da Saúde; 1984.

21. Ministério da Saúde (BR). Secretaria Executiva. Coordenação da Saúde da Criança e do Adolescente. Programa do adolescente: bases programáticas. $2^{\mathrm{a}}$ ed. Brasília (DF): Ministério da Saúde; 1996.

22. Ministério da Saúde (BR). Secretaria de Projetos Especiais de Saúde. Coordenação Nacional de DST e AIDS. Documento de referência para trabalho de prevenção das DST, AIDS e drogas: criança, adolescente e adulto jovem. Brasília (DF): Ministério da Saúde; 1997. 23. Ministério da Saúde (BR). Secretaria de Assistência à Saúde. Manual para a organização da atenção básica. Brasília (DF): Ministério da Saúde; 1999. 